\title{
Effect of Sintering Temperature on the Micro Strain and Magnetic Properties of Ni-Zn Nanoferrites
}

\author{
D. Venkatesh ${ }^{1}$, M. Siva Ram Prasad ${ }^{2}$, B. Rajesh Babu' ${ }^{3}$ K. V. Ramesh ${ }^{1 *}$, and K. Trinath ${ }^{4}$ \\ ${ }^{1}$ Center for Materials Research, Department of Physics, GIT, GITAM University, Rushikonda, Visakhapatnam, India \\ ${ }^{2}$ Department of Physics, M.V.G.R College of Engineering, Vizianagaram, India \\ ${ }^{3}$ Department of Physics, GVP College of Engineering for Women, Visakhapatnam, India \\ ${ }^{4}$ Naval Science and Technological Laboratory, DRDO, Vigyan Nagar, Visakhapatnam, India
}

(Received 24 January 2015, Received in final form 12 June 2015, Accepted 12 June 2015)

\begin{abstract}
In this study, nanocrystalline ferrite powders with the composition $\mathrm{Ni}_{0.5} \mathrm{Zn}_{0.5} \mathrm{Fe}_{2} \mathrm{O}_{4}$ were prepared by the autocombustion method. The obtained powders were sintered at $800^{\circ} \mathrm{C}, 900^{\circ} \mathrm{C}$ and $1,000^{\circ} \mathrm{C}$ for $4 \mathrm{~h}$ in air atmosphere. The as-prepared and the sintered powders were characterized by X-ray diffraction (XRD), Fourier transform infrared (FT-IR) spectroscopy, and magnetization studies. An increase in the crystallite size and a slight decrease in the lattice constant with sintering temperature were observed, whereas microstrain was observed to be negative for all the samples. Two significant absorption bands in the wave number range of the $400 \mathrm{~cm}^{-1}$ to $600 \mathrm{~cm}^{-1}$ have been observed in the FT-IR spectra for all samples which is the distinctive feature of the spinel ferrites. The force constants were found to vary with sintering temperature, suggesting a cation redistribution and modification in the unit cell of the spinel. The M-H loops indicate smaller coercivity, which is the typical nature of the soft ferrites. The observed variation in the saturation magnetization and coercivity with sintering temperature has been attributed to the role of surface, inhomogeneous cation distribution, and increase in the crystallite size.
\end{abstract}

Keywords : nano, ferrite, citrate gel auto-combustion, sintered, XRD, IR, M-H loop, coercivity

\section{Introduction}

The nanoscaled spinel ferrites have drawn significant scientific attentionin the recent past owing to their functional applications in the magnetic information storage, electronic devices, ferrofluid technology, sensors, MRI, target drug delivery, etc. [1]. The magnetic, structural and electrical properties of these nanometric ferrites are conspicuous and differ largely compared to their bulk counterparts, and have a great deal of interesting theoretical aspects. For instance, Yang et al. observed an enhancement in the Neel temperature of $\mathrm{MnFe}_{2} \mathrm{O}_{4}$ nanoparticles compared to its bulk conuterpart, synthesized by the modified coprecipitation method with particle sizes in the range 4-50 $\mathrm{nm}$. The Neel temperature has been reported to increase with particle size and is attributed to the cation redistribution, which significantly modifies the

(C)The Korean Magnetics Society. All rights reserved.

*Corresponding author: Tel: +91-984-829-2228

Fax: +91-891-279-0399, e-mail: kvramesh11@gmail.com strength of the superexchange interactions largely, whereas the surface chemistry, structure, and the magnetic spin configuration are reported to play secondary roles [2]. Similarly, Šepelák et al. observed an enhancement in the magnetization of nanosized $\mathrm{MgFe}_{2} \mathrm{O}_{4}$ particles with an average size of $8.5 \mathrm{~nm}$ synthesized by the mechanochemical route. Using Mossbauer spectroscopy, the authors confirmed the core-shell structure of nanoparticles with a Neel type collinear arrangement of core and a surface with a non equilibrium cation distribution and a canted spin arrangement. On sintering the $\mathrm{MgFe}_{2} \mathrm{O}_{4}$ nanoparticles above $623 \mathrm{~K}$, the restoration of the normal site preferences of the cations has been observed [3]. John Jacob and M. Abdul Khadar reported a mixed spinel structure for the nanosized $\mathrm{NiFe}_{2} \mathrm{O}_{4}$ synthesized by the coprecipitation technique.

This fine particle size effects have been assigned to the surface spin canting and change in the iron ion coordination at the tetrahedral and octahedral sites. Bulk configuration with normal site preferences of the cations has been restored on sintering at $750^{\circ} \mathrm{C}$ for $2 \mathrm{~h}$ with 
particle sizes of $51 \mathrm{~nm}$ [4]. Upadhaya et al. [5] reported large cation inversion for zinc ferrite synthesized by two procedures, namely, the citrate precursor and the hydrothermal synthesis with particle size of 4 and $6 \mathrm{~nm}$ respectively.

The above metioned literature review indicate that the properties of the nanoferrites are conspicuous and differ largely compared to their bulk equivalents and are all attributed to the finite size effects arising at the nanoscale.

Amongst the nanoscaled soft ferrites, the study of the magnetic, structural, hyperfine and morphological properties of the Ni-Zn ferrites has been receiving substantial attention in the recent years owing to their high magnetization, Curie temperature, chemical stability, low coercivity, biodegradability [1], and the fascinating complex magnetic interactions involved among the cations at the nano range. The Ni-Zn ferrite crystallizes in the FCC structure having the space group $\mathrm{Fd} 3 \mathrm{~m}$. Among the available 96 interstitial in the $\mathrm{Ni}-\mathrm{Zn}$ spinel ferrite unit cell, 64 are tetrahedral (A) and 32 are octahedral [B] sites, out of which $\frac{1}{8}$ of the tetrahedral and $\frac{1}{2}$ of the octahedral sites are occupied by cations. In the usual cation distribution for Ni-Zn ferrite, all the $\mathrm{Zn}^{2+}$ ions are located at the A sites only because of $\mathrm{sp}^{3}$ hybridization, and the $\mathrm{Ni}^{2+}$ ions because of their high crystal field stabilization occupy octahedral sites only when the $\mathrm{Fe}^{3+}$ ions are distributed among both the sites [6]. At the nanoregime, large deviations in the site preferences of the cations and magnetic behavior of Ni-Zn ferrites have been reported which strongly depend on the method of preparation. Beji et al. [7] reported the occupancy of both the $\mathrm{Ni}^{2+}$ and $\mathrm{Zn}^{2+}$ ions to $\mathrm{A}$ and $\mathrm{B}$ sites with a random distribution in Ni-Zn ferrite $\left(\mathrm{Ni}_{1-\mathrm{x}} \mathrm{Zn}_{\mathrm{x}} \mathrm{Fe}_{2} \mathrm{O}_{4}, \mathrm{x}=0.2\right.$ and 0.4$)$ processed through the polyol route. Restoration of the bulk configuration has been observed on sintering powders at $\geq 600^{\circ} \mathrm{C}$. The magnetization studies displayed a superparamagnetic behavior for the as-prepared and sintered powders at $400^{\circ} \mathrm{C}$ with the blocking temperature $\left(T_{B}\right)$ below room temperature. Gubbala et al. [8] reported the measured magnetic properties of $\mathrm{Ni}_{0.5} \mathrm{Zn}_{0.5} \mathrm{Fe}_{2} \mathrm{O}_{4}$ prepared by the reverse micelle technique using SQUID at low temperatures (upto $2 \mathrm{~K}$ ). A nonsaturated $\mathrm{M}-\mathrm{H}$ loops have been reported at room temperature and also at $2 \mathrm{~K}$ even for a field as high as $5 \mathrm{~T}$ with a nonzero remenence and coercivity at $2 \mathrm{~K}$. The lower value of $\mathrm{M}_{\mathrm{S}}$ for the nanoparticles of Ni-Zn ferrite compared to the bulk value is attributed to the core-shell morphology of the particles consisting of the ferrimagnetically aligned core spins and spin-glass like surface. Thakur et al. [9] reported the observations on the structural, magnetic and Mossbauer characterization of the AP $\mathrm{Ni}_{0.58} \mathrm{Zn}_{0.42} \mathrm{Fe}_{2} \mathrm{O}_{4}$ nanoparticles and sintered at 1,473 $\mathrm{K}$ synthesized via the reverse micelle technique. Using Mossbauer spectroscopy, the authors confirmed a departure from the usual site preferences of the cations and a spin canting at the surface, while the spins in the cores are aligned ferrimagnetically with a Neel type of collinear spin arrangement. The thickness of the surface was estimated to be $\sim 1.3 \mathrm{~nm}$ from the magnetization measurements. The sintered $\mathrm{Ni}_{0.58} \mathrm{Zn}_{0.42} \mathrm{Fe}_{2} \mathrm{O}_{4}$ at $1,473 \mathrm{~K}$ corresponds to the bulk material with a normal site preference for the cations, and the authors suggested that the nonequilibrium cation distribution and the canted spin arrangement resulting from the reverse micelle route is metastable, indicating that sintering restores an equilibrium configuration. Upadhyay et al. [10] studied the cation distribution of the nanosized Ni-Zn ferrites prepared by the chemical coprecipitation method followed by the hydrothermal treatment using Mossbauer spectroscopy. The authors confirmed the restitution of the regular site preference of the cations upon sintering at $\geq 1,000^{\circ} \mathrm{C}$.

Considering the above factors, in this study, we report the effect of sintering on the microstructure and magnetic properties of $\mathrm{Ni}_{0.5} \mathrm{Zn}_{0.5} \mathrm{Fe}_{2} \mathrm{O}_{4}$ prepared by the nitratecitrate gel auto-combustion method at temperatures of 800,900 , and $1,000^{\circ} \mathrm{C}$ for $4 \mathrm{~h}$ in air atmosphere. The auto-combustion method was selected, because it is relatively a low temperature process, less time consuming and provides a homogenous particle size distribution. The composition of $\mathrm{Ni}_{0.5} \mathrm{Zn}_{0.5} \mathrm{Fe}_{2} \mathrm{O}_{4}$ was selected owing to its high saturation magnetization in the $\mathrm{Ni}-\mathrm{Zn}$ ferrite family [11]. Here after, the samples were labelled as: AP (as-prepared), and 800, 900, and 1,000 (for sintered $\mathrm{Ni}_{0.5} \mathrm{Zn}_{0.5} \mathrm{Fe}_{2} \mathrm{O}_{4}$ powders at $800,900,1,000^{\circ} \mathrm{C}$, respectively).

\section{Experimental}

\subsection{Preparation}

In our previous communication, we reported the detailed procedure for preparing the Ni-Zn ferrite nanopowders via the citrate-gel autocombustion route [12]. In a typical experiment, citric acid was added to the stoichimetric mixture solution of metal nitrate salts at $65^{\circ} \mathrm{C}$ under continuous stirring and constant heating. The solution was boiled and frothed, because of the evolution of water and gradually converted to a viscous gel. The thickness of the gel increased with increase of temperature until a reddish gel was formed with the emission of reddish brown gases. The gel further self ignited and burned, leaving behind a fluffy mass residue. The AP and the sintered powders at 800,900 and $1,000^{\circ} \mathrm{C}$ were characterized by X-ray diffraction (XRD), VSM, and 
Fourier transform infrared (FT-IR) spectroscopy for structural and magnetic studies.

\subsection{XRD}

The powder XRD pattern of the AP $\mathrm{Ni}_{0.5} \mathrm{Zn}_{0.5} \mathrm{Fe}_{2} \mathrm{O}_{4}$ and sintered powders were recorded using a Pan-analytical X'Pert-PRO diffractometer using $\mathrm{Cu}_{-\mathrm{K} \alpha}$ radiation $(\lambda=$ $1.5406 \AA$ ). The formation of the spinel ferrite phase was confirmed by the JCPDS files [13]. The inter-planar spacing was obtained from the Intensity Vs. $2 \theta$ plot using the Braggs Law [14].

\subsection{Magnetization studies}

Room temperature $\mathrm{M}-\mathrm{H}$ loops were recorded using a Lakeshore VSM Magnetometer (Model 7410 for a maximum magnetic field of 1.5 Tesla). The saturation magnetization, remenance, and coercivity were obtained from the $\mathrm{M}-\mathrm{H}$ loops.

\subsection{FT IR Spectra}

The FT IR spectral studies were performed using the Shimadzu Prestiage-21 FT IR spectrometer in the standard $\mathrm{KBr}$ medium at room temperature in the wavenumber range $300-1,000 \mathrm{~cm}^{-1}$.

\section{Results and Discussion}

\subsection{XRD study}

The XRD patterns of the AP and sintered powder samples of $\mathrm{Ni}_{0.5} \mathrm{Zn}_{0.5} \mathrm{Fe}_{2} \mathrm{O}_{4}$ at 800,900 , and $1,000^{\circ} \mathrm{C}$, shown in Figs. 1(a) and 2(a), indicate the formation of the spinel ferrite phase, suggesting the solubility of the cations into their respective lattice sites. The interplanar spacing has been obtained using the Bragg's law. The lattice constant corresponding to each peak of the diffraction pattern was plotted against the Nelson-Riley error function [14] $\left(\mathrm{F}(\theta)=\frac{1}{2}\left(\frac{\operatorname{Cos}^{2} \theta}{\operatorname{Sin} \theta}+\frac{\operatorname{Cos}^{2} \theta}{\theta}\right)\right)$, and the accurate lattice constant, corresponding to zero error, was obtained by the least square fit. The lattice constant (Table 1) of the AP sample was found to be $8.397 \AA$, which is in well comparison with the reported values $[10,15]$. The crystallite size of the AP powder particles as determined by the Scherrer formula was $18 \mathrm{~nm}$ (Table 1) [16] using the intense (311) peak. A considerable broadening of the XRD lines was observed for the AP samples, which is the characteristic of the nanoregime, and the broadening is normally attributed to the crystallite size and lattice strain. The contributions of the size and the strain broadening to the XRD lines can be well separated if the diffraction peaks obey either Gaussian or Lorentzian profiles [16]. In this study, the diffraction peaks observed were in full accordance with the Gaussian profile than that of Lorentzian's shown in Figs. 1(b) and 2(b). The lattice strain or the microstrain was determined using the Hall-Williamson plot $\operatorname{Sin} \theta$ is in accordance to the expression $\frac{\beta \operatorname{Cos} \theta}{\lambda}=$ $\frac{k}{D}+\eta \frac{\operatorname{Sin} \theta}{\lambda}[16]$, where $\beta$ is the full width at half maximum (FWHM) of the diffracted peak after correction to

Table 1. Lattice constant (exp.), crystallite size, micro strain, $d_{X}$, SSA, of the AP and powders sintered $\mathrm{Ni}_{0.5} \mathrm{Zn}_{0.5} \mathrm{Fe}_{2} \mathrm{O}_{4}$ at $800^{\circ} \mathrm{C}, 900^{\circ} \mathrm{C}$, and $1,000^{\circ} \mathrm{C}$.

\begin{tabular}{cccccc}
\hline \hline Sample & $\begin{array}{c}\mathrm{a} \\
(\AA)\end{array}$ & $\begin{array}{c}\mathrm{D} \\
(\mathrm{nm})\end{array}$ & $\eta$ & $\begin{array}{c}d_{X} \\
\left(\mathrm{gm} / \mathrm{cm}^{3}\right)\end{array}$ & $\begin{array}{c}\mathrm{SSA} \\
\left(\mathrm{gm} / \mathrm{cm}^{2}\right)\end{array}$ \\
\hline $\mathrm{AP}$ & 8.3970 & 18 & -0.00466 & 5.33 & 62.54 \\
800 & 8.3915 & 32 & -0.000707 & 5.48 & 34.21 \\
900 & 8.3933 & 34 & -0.00117 & 5.34 & 33.00 \\
1000 & 8.3923 & 35.7 & -0.0021 & 5.34 & 31.47 \\
\hline
\end{tabular}

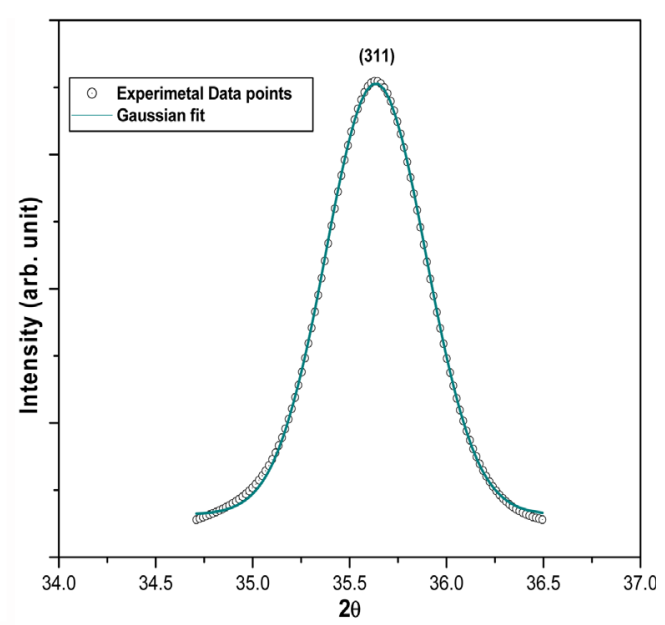

(b)

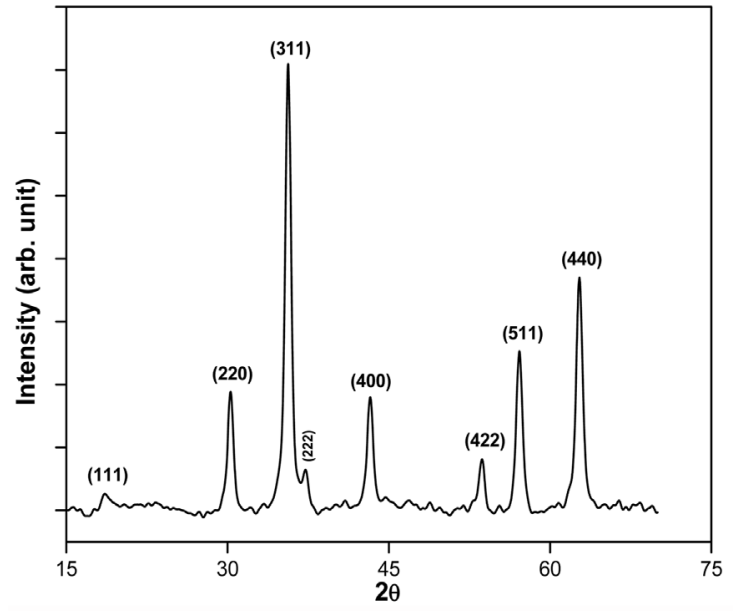

(a)

Fig. 1. (Color online) (a) XRD pattern of the $\mathrm{AP} \mathrm{Ni}_{0.5} \mathrm{Zn}_{0.5} \mathrm{Fe}_{2} \mathrm{O}_{4}$; (b) Gaussian profile fit of the (311) peak. 


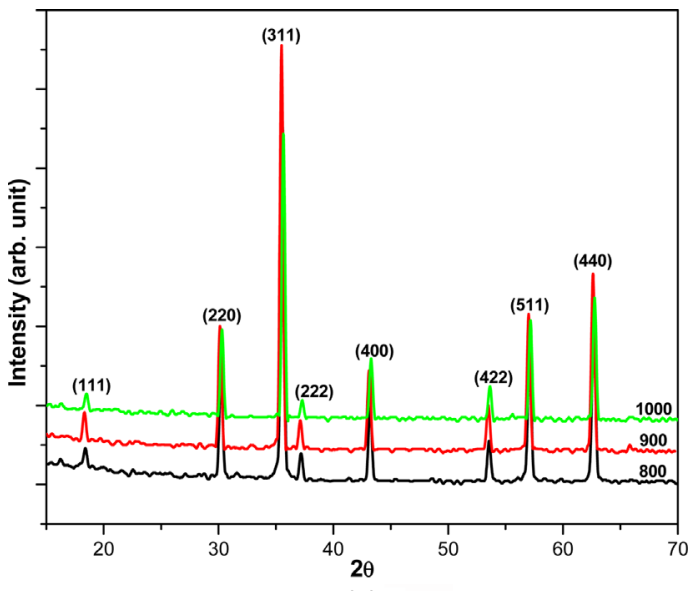

(a)

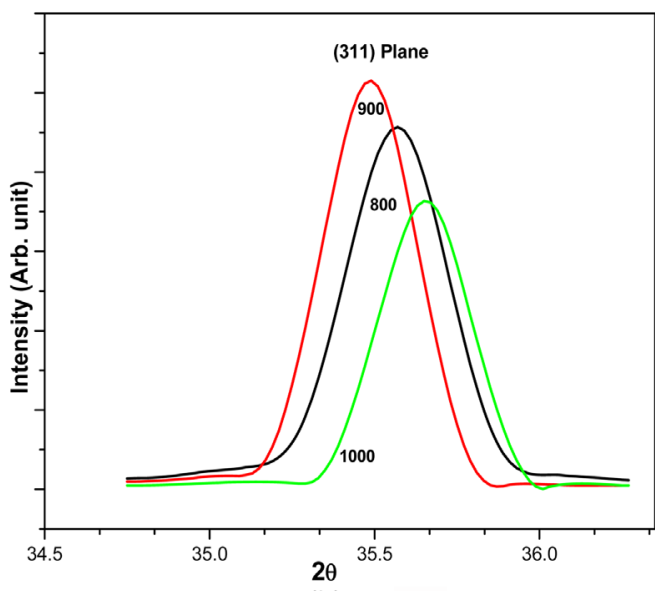

(b)

Fig. 2. (Color online) (a) XRD pattern of sintered $\mathrm{Ni}_{0.5} \mathrm{Zn}_{0.5} \mathrm{Fe}_{2} \mathrm{O}_{4}$ at 800,900 , and $1,000^{\circ} \mathrm{C}$; (b) (311) peaks.
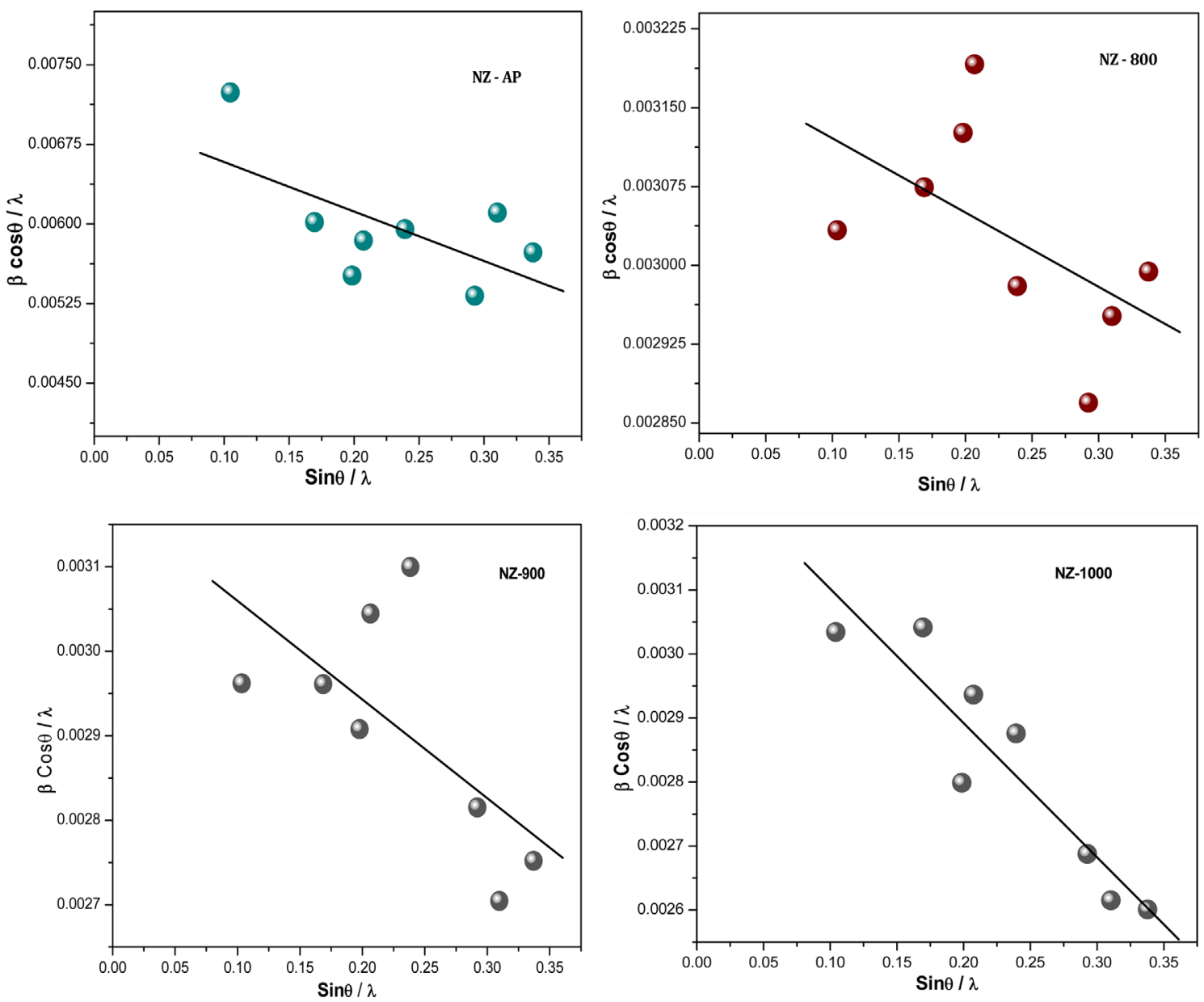

Fig. 3. (Color online) W-H Plots of $\mathrm{AP}$ and sintered $\mathrm{Ni}_{0.5} \mathrm{Zn}_{0.5} \mathrm{Fe}_{2} \mathrm{O}_{4}$ at $800^{\circ} \mathrm{C}, 900^{\circ} \mathrm{C}$, and $1,000^{\circ} \mathrm{C}$.

instrumentation broadening $\left(\beta=\sqrt{\beta_{\exp }^{2}-\beta_{\text {ins }}^{2}}\right) ; \mathrm{k}(=1)$ is the Scherer factor; $\eta$ is the lattice strain; and $\lambda$ is the wavelength of the X-Ray beam. Here, $\beta_{\text {exp }}$ is the experimental FWHM and $\beta_{\text {ins }}$ is the instrumentation broadening factor (found to be $0.06^{\circ}$, obtained from the scans of the standard silicon powder, and $\theta$ is the corresponding Bragg angle of diffraction in radians). The graphs of $\frac{\beta \cos \theta}{\lambda}$ versus $\frac{\operatorname{Sin} \theta}{\lambda}$ shown in Fig. 3 are straight lines with slope $\eta$ 


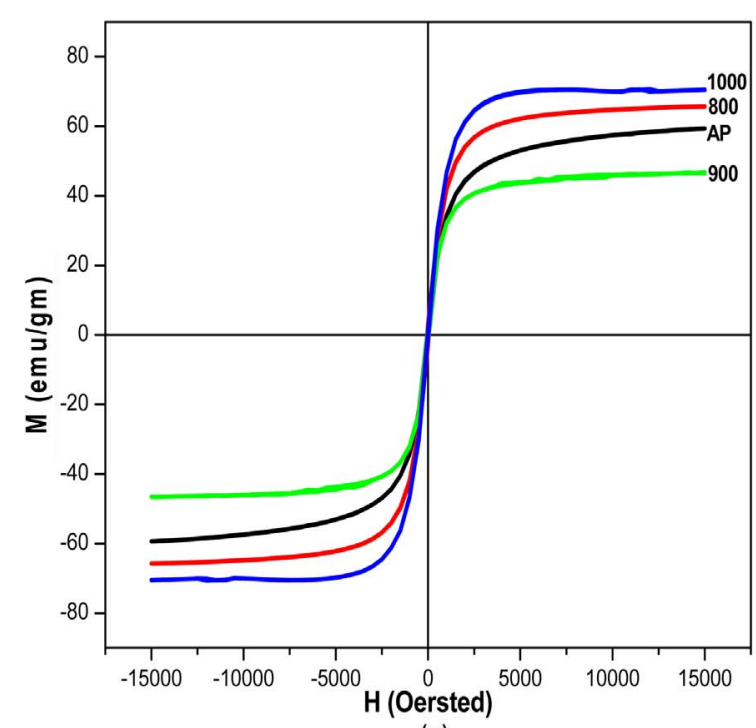

(a)

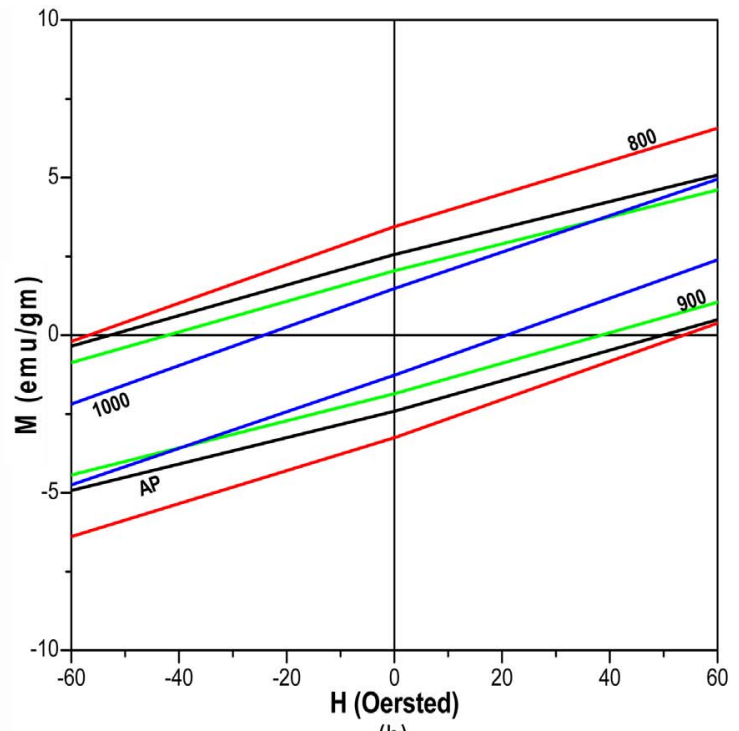

(b)

Fig. 4. (Color online) (a-b): Room temperature $\mathrm{M}-\mathrm{H}$ loops of $\mathrm{AP} \mathrm{Ni}_{0.5} \mathrm{Zn}_{0.5} \mathrm{Fe}_{2} \mathrm{O}_{4}$ and powder sintered at $800^{\circ} \mathrm{C}$, $900^{\circ} \mathrm{C}$, and $1,000^{\circ} \mathrm{C}$.

from which the microstrain can be directly obtained.

The theoretical density $\left(\mathrm{d}_{\mathrm{X}}\right)$ and the specific surface area (SSA), shown in Table 1, were determined using the expressions $d_{X}=\frac{Z M}{N a^{3}}$ and $S S A=\frac{6000}{d \cdot D}$ [17] respectively, where $\mathrm{Z}(=8)$ is the number of molecules in the unit cell of the spinel; $\mathrm{M}$ is the molecular weight; $\mathrm{N}$ is the Avogadro number; $a$ is the experimental lattice constant; and $\mathrm{D}$ is the particle size obtained from the XRD, assuming that the nanoparticles are spherical. The XRD patterns of the sintered powders show a single phase spinel structure [13] with lattice constant values lower than those of the AP sample, whereas the crystallite size improved with sintering. This is evident from the decrease in the FWHM of the diffraction peaks with sintering temperature, indicating an improvement in the crystallization process by elimination of defects such as voids or vacancies, crystallite growth, and crystallite coalescence. The SSA, representing the surface to volume ratio, decreased with sintering temperature. The compressive lattice strain for the sintered powders was lower in comparison to that of the AP sample.

\subsection{Magnetization studies}

The M-H loops of $\mathrm{Ni}_{0.5} \mathrm{Zn}_{0.5} \mathrm{Fe}_{2} \mathrm{O}_{4}$ recorded at room temperature (Fig. 4(a)) shows a nonsaturated specific magnetization in the case of the AP and sintered powder at $800^{\circ} \mathrm{C}$ even under a high magnetic field of $1.5 \mathrm{~T}$. The sample sintered at $900^{\circ} \mathrm{C}$ showed a near magnetic saturation, and a complete saturation of the $\mathrm{M}-\mathrm{H}$ loop was observed for the sample sintered at $1,000^{\circ} \mathrm{C}$ with the
Table 2. Saturation magnetization $\left(\mathrm{M}_{\mathrm{s}}\right)$, Remenance $\left(\mathrm{M}_{\mathrm{r}}\right)$, coercivity $\left(\mathrm{H}_{\mathrm{c}}\right)$, and $M_{r} / M_{s}$ ratio of the $\mathrm{AP}$, and powders sintered $\mathrm{Ni}_{0.5} \mathrm{Zn}_{0.5} \mathrm{Fe}_{2} \mathrm{O}_{4}$ at $800^{\circ} \mathrm{C}, 900^{\circ} \mathrm{C}$, and $1,000^{\circ} \mathrm{C}$.

\begin{tabular}{|c|c|c|c|c|}
\hline Sample & $\begin{array}{c}\mathrm{M}_{\mathrm{s}} \\
(\mathrm{emu} / \mathrm{gm})\end{array}$ & $\begin{array}{c}\mathrm{M}_{\mathrm{r}} \\
(\mathrm{emu} / \mathrm{gm})\end{array}$ & $\begin{array}{c}\mathrm{H}_{\mathrm{c}} \\
\text { (Oersted) }\end{array}$ & $\frac{M_{r}}{M_{s}}$ \\
\hline $\mathrm{AP}$ & 61.00 & 2.484 & 51.29 & 0.0407 \\
\hline 800 & 67.00 & 3.350 & 55.215 & 0.0500 \\
\hline 900 & 48.12 & 1.948 & 40.192 & 0.0405 \\
\hline 1000 & 70.53 & 1.373 & 22.500 & 0.0195 \\
\hline
\end{tabular}

saturation magnetization (Table 2) equal to that of the bulk (70 emu/gm [8]). Fig. 5 shows the saturation magnetization of the AP and the powders sintered at 800 and $900^{\circ} \mathrm{C}$ determined from the law of approach to saturation through the extrapolation of $\mathrm{M}$ versus $\frac{1}{H}$ graph to $\frac{1}{H}=0$ [18]. Saturation values of 61 and $67 \mathrm{emu} / \mathrm{gm}$ were obtained for the AP and sintered powder at $800^{\circ} \mathrm{C}$ respectively, whereas an abnormal decrease in the saturation magnetization to $48.12 \mathrm{emu} / \mathrm{gm}$ was observed for the sample sintered at $900^{\circ} \mathrm{C}$. The lower saturation magnetization of the AP $\mathrm{Ni}_{0.5} \mathrm{Zn}_{0.5} \mathrm{Fe}_{2} \mathrm{O}_{4}(61 \mathrm{emu} / \mathrm{gm})$ nanoparticles compared to the bulk $(70 \mathrm{emu} / \mathrm{gm})$ is attributed to the finite particle size effects arising at the nanoscale. The AP $\mathrm{Ni}_{0.5} \mathrm{Zn}_{0.5} \mathrm{Fe}_{2} \mathrm{O}_{4}$ powder particles are essentially in a single domain, as their size $(18 \mathrm{~nm})$ is considerably less than the critical particle size $(22.3 \mathrm{~nm})$ for the isolated $\mathrm{Ni}-\mathrm{Zn}$ ferrite nanoparticles [7]. In such single domain fine particles, the lower value of the magnetization than that of the bulk materials is ascribed 


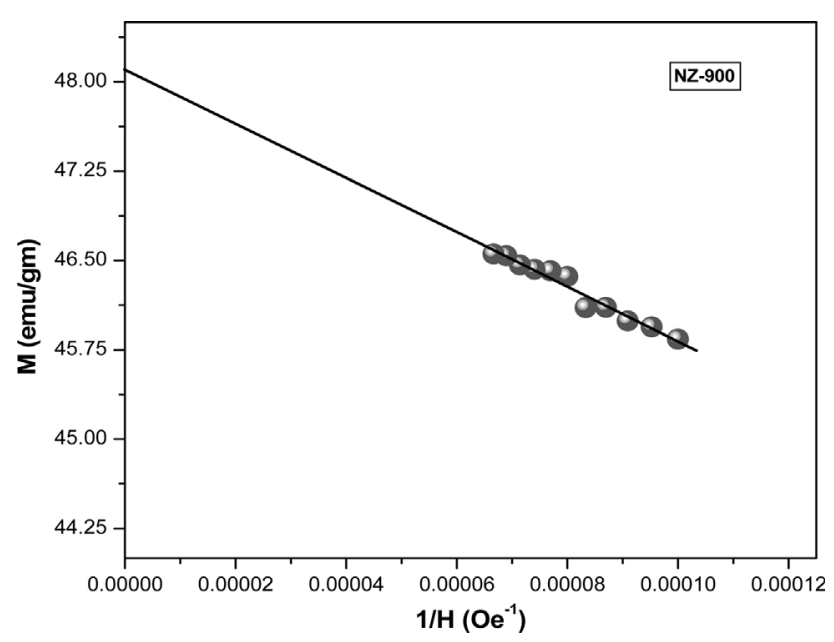

Fig. 5. Graph showing the law of approach to saturation in powder sintered $\mathrm{Ni}_{0.5} \mathrm{Zn}_{0.5} \mathrm{Fe}_{2} \mathrm{O}_{4}$ at $900^{\circ} \mathrm{C}$.

to the existence of the magnetically disordered surface surrounding the particle and can be understood from the core-shell morphology of the nano particles proposed by Kodama and coworkers [19]. According to the core-shell structure of such nanoparticles, the core is ferrimagnetically ordered, in which the magnetic spins of the cations on the $\mathrm{A}$ and $\mathrm{B}$ sites are bound by strong exchange interactions, whereas an incongruity exists on the spin arrangement at the surface. The anomaly in the spin arrangement at the surface of the nanoparticles might be because of the presence of broken exchange bonds, reduced coordination, and absence of the long range order and hence the surface is of spin glass type. These effects are more intense in the case of ferrites, because the magnetic properties of ferrites are governed mainly by the superexchange or the indirect exchange interactions among the cations at the $\mathrm{A}$ and $\mathrm{B}$ sites are $\mathrm{O}^{2-}$-ion mediated, and hence the absence of oxygen or the presence of any other ions would dramatically modify the magnetic characteristics of the surface in comparison to the core $[3,8,19$, 20]. Moreover, the superexchange interactions are significantly affected by the bond angle and bond lengths, and thus reduced coordination or termination of bonds would introduce a large surface spin disorder. Because of the termination of bonds at the surface, there is a distribution of the net exchange fields, and the asymmetric oxygen ion coordination at the surface cation sites causes large perturbation to the crystal field, resulting in radial uniaxial surface anisotropy [20], and such effects are very dominating for the particles with diameters very smaller compared to the critical particle size because of their hefty SSA. The nonsaturating M-H loop (Fig. 4(a)) of the AP powder particles of $\mathrm{Ni}_{0.5} \mathrm{Zn}_{0.5} \mathrm{Fe}_{2} \mathrm{O}_{4}$ even at an applied magnetic field as high as $1.5 \mathrm{~T}$ is attributed again to the presence of a spin-glass like surface surrounding the nanoparticles. This possibility can be expected, because the AP $\mathrm{Ni}_{0.5} \mathrm{Zn}_{0.5} \mathrm{Fe}_{2} \mathrm{O}_{4}$ nanoparticles were found to possess a high SSA (Table 1), and hence a greater surface to volume ratio compared to the sintered powders. In the case of the bulk particles, there is a virtual absence of the surface layer, and thus the contribution to the total magnetization is only because of the core. Moreover, in the presence of an increasing external field, the core magnetization increases with increasing field and finally attains magnetic saturation. However, the situation is entirely different for the fine nanoparticles, because of the presence of magnetically inactive surface, and in such a situation, the total magnetization of the particle has contributions from both the core and the surface. When such fine particles are placed in an increasing magnetic field, at the initial stage, the core moments align with the applied magnetic field, and at some juncture, the core gets completely aligned in the direction of the field in a usual Langevin way, and any further increase in the field affects only the surface layer, thus the increase in the magnetization of the particles slows down. Moreover, the disordered surface is a large source of anisotropy which aligns the spins on the surface perpendicular and thus requires fairly higher magnetic fields for aligning the surface moments in the field direction and such a possibility generates virtual absence of the magnetic saturation even for very strong fields [8]. The thickness $(t)$ of the surface layer of $\mathrm{Ni}_{0.5} \mathrm{Zn}_{0.5} \mathrm{Fe}_{2} \mathrm{O}_{4}$ nanoparticles is determined from the linear fitting of the saturation magnetization versus $1 / \mathrm{D}$ according to the relation $\mathrm{M}_{\mathrm{S}}=\mathrm{M}_{\mathrm{Bulk}}\left(1-\frac{6 \mathrm{t}}{\mathrm{D}}\right)$ [18], where D is the particle diameter (from the Scherrer equation) and $\mathrm{M}_{\mathrm{Bulk}}(70 \mathrm{emu} / \mathrm{gm})$ is the saturation magnetization of bulk assuming spherical shape of the nanocrystallites. The thickness of the surface of the nanoparticles of $\mathrm{Ni}_{0.5} \mathrm{Zn}_{0.5} \mathrm{Fe}_{2} \mathrm{O}_{4}$ was estimated to be $1 \mathrm{~nm}$ (Fig. 6) and is in well comparison with $\mathrm{Ni}_{0.5} \mathrm{Zn}_{0.5} \mathrm{Fe}_{2} \mathrm{O}_{4}$ prepared by a different synthesizing procedure [9]. By sintering $\mathrm{Ni}_{0.5} \mathrm{Zn}_{0.5} \mathrm{Fe}_{2} \mathrm{O}_{4}$ powders in the temperature range $800-1,000^{\circ} \mathrm{C}$, a gradual decrease in the surface was observed and reflected by the slow appearance of the magnetic saturation, which was completely attained at $1,000^{\circ} \mathrm{C}$. The observed variation in the specific saturation magnetization (Table 2) of $\mathrm{Ni}_{0.5} \mathrm{Zn}_{0.5} \mathrm{Fe}_{2} \mathrm{O}_{4}$ with sintering temperature in the range $800-1,000^{\circ} \mathrm{C}$ is discussed in detail below.

(a) In general, an increase in the saturation magnetization is usually expected with an increase in the sintering temperature, because the heat treatment promotes grain growth and improves the structural and chemical homo- 


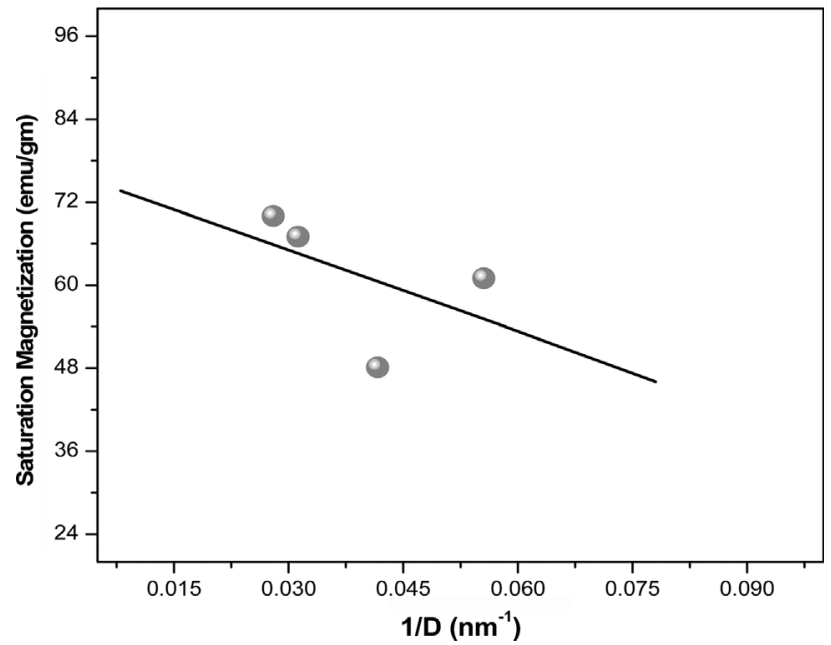

Fig. 6. Linear fit of $\mathrm{M}_{\mathrm{s}}$ Vs. 1/D for $\mathrm{Ni}_{0.5} \mathrm{Zn}_{0.5} \mathrm{Fe}_{2} \mathrm{O}_{4}$ at $300 \mathrm{~K}$.

geneity of the powders by the elimination of the defects such as dislocations and stacking faults and thereby increasing the magnetization [7]. The observed increase in the magnetization in the $\mathrm{Ni}_{0.5} \mathrm{Zn}_{0.5} \mathrm{Fe}_{2} \mathrm{O}_{4}$ nanopowder sintered at $800^{\circ} \mathrm{C}$ can be assigned to the above discussed factors, because the increase in the crystallite size $(32 \mathrm{~nm})$ well above the critical size $(22.3 \mathrm{~nm})$ suggests the formation of multidomain structure and thereby an increase in the magnetization is facilitated by the domain wall motion accompanied by an expected decrease in the magnetic coercivity. Another significant contribution to the magnetization arises from the possible cation redistribution at the nanoscale in Ni-Zn ferrite observed from the large modification in the exchange interactions and anisotropic characteristics of the sample and will be discussed in the next section.

(b) In contrast to the expected result, a sudden drop in the magnetization (to $48.12 \mathrm{emu} / \mathrm{gm}$ ) was observed, when the $\mathrm{Ni}_{0.5} \mathrm{Zn}_{0.5} \mathrm{Fe}_{2} \mathrm{O}_{4}$ nanopowder was sintered at still higher temperature of $900^{\circ} \mathrm{C}$ despite the increase in the crystallite size (Table 1). Swaminathan et al. reported a similar decrease in the magnetization of Ni-Zn ferrite on the sintering prepared by the RF plasma technique. The initial decrease in the magnetic moment at lower sintering temperatures is assigned to the $\mathrm{Zn}$ diffusing from the core depleting the ferrite and occupying the surface in the form of $\mathrm{ZnO}$, and thereby formation of nanoparticles with the $\mathrm{Zn}$ rich surface and Ni rich core. The anomaly observed in the magnetization on sintering in the temperature range $900-1,000^{\circ} \mathrm{C}$ is attributed to the formation of elemental $\mathrm{Ni}-\mathrm{NiO}$ in the core for the Ni-rich region of the ferrite, and on sintering at still higher temperature of $1,100^{\circ} \mathrm{C}$ the further drastic drop in magnetization is attributed to the conversion of all $\mathrm{NiO}$ to elemental Nickel $[21,22]$. The formation of $\mathrm{NiO}$ (more probable on sintering in air atmosphere) is extremely difficult to detect by XRD technique, because it displays the diffraction peaks at about the same angles for the spinel ferrite. In this study, the XRD patterns of the sintered powders of $\mathrm{Ni}_{0.5} \mathrm{Zn}_{0.5} \mathrm{Fe}_{2} \mathrm{O}_{4}$ in the temperature range of $800-1,000^{\circ} \mathrm{C}$ showed the characteristics of the single spinel phase with the lattice constants very close to the reported values. This observation can be explained by considering an inhomogeneous cation distribution, because of the possible migration of $\mathrm{Zn}^{2+}$ ions in a substantial fraction from the $\mathrm{A}$ to the Bsites of the spinel lattice accompanied by the migration of equal number of $\mathrm{Fe}^{3+}$ ions from $\mathrm{B}$ to $\mathrm{A}$ sites. This possibly induces a large increase in the lattice strain in comparison to the strain at $800^{\circ} \mathrm{C}$ and is apparent from the measurements using the W-H plots (Table 1). Such possible migration of the $\mathrm{Zn}^{2+}\left(0 \mu_{\mathrm{B}}\right)$ and $\mathrm{Fe}^{3+}\left(5 \mu_{\mathrm{B}}\right)$ ions would result in a decrease in the net magnetic moment of the Bsites, whereas the magnetic moment of A sites would increase, and thereby the total magnetic moment of the spinel lattice, which is just the difference of the magnetic moments of the A and B sites, would decrease, thus reducing the total magnetization of the sample. The other factor which is largely affected by this inhomogeneous cation distribution is the exchange interaction mechanisms occurring among the cations on the A and $\mathrm{B}$ magnetic sublattices. In the spinel structure, the metal ions on the octahedral B-sites have strong superexchange interactions with six metal ions on the tetrahedral A-sites, whereas the ions on the A-sites are strongly coupled with twelve neighbouring metal ions on the B-sites. Hence, through a given oxygen ion, a B-site cation interacts with only one A-site ion, whereas an A-site ion interacts with three nearest-neighboring B-site ions. Because of their relatively larger separation $(\sim 3.5 \AA)$ the A-site cations are not expected to have detectable interactions with other Asite cations. In general, a B-site cation interacts though rather weakly with another B-site cation only by a direct overlap or through $90^{\circ}$ superexchange interaction [23]. The above depiction hints that the strongest oxygen mediated superexchange interaction is the A-O-B in comparison to the B-O-B and A-O-A arrangement. From the above understanding, it is clear that any possible cation shifting from $A$ to $B$ sites or vice versa would strongly affect the A-O-B exchange interaction mechanism, and thereby leads to dramatic variation in the net magnetization, which is observed in this study for the sintered powder of $\mathrm{Ni}_{0.5} \mathrm{Zn}_{0.5} \mathrm{Fe}_{2} \mathrm{O}_{4}$ at $900^{\circ} \mathrm{C}$. This is due to the fact that the migration of $\mathrm{Zn}^{2+}$ from $\mathrm{A}$ to $\mathrm{B}$ sites and possible relocation of the equal number of $\mathrm{Fe}^{3+}$ ions from the $\mathrm{B}$ to $\mathrm{A}$-sites would generate large alteration in 


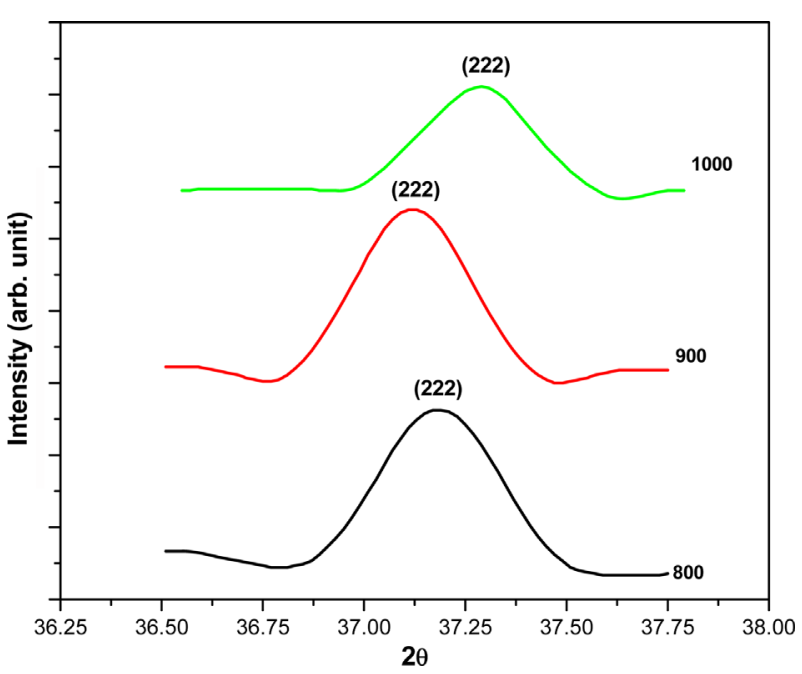

Fig. 7. (Color online) Positions of the (222) peak with sintering temperature of $\mathrm{Ni}_{0.5} \mathrm{Zn}_{0.5} \mathrm{Fe}_{2} \mathrm{O}_{4}$.

the exchange interaction mechanism among the cations on the A and B-sites.

One can anticipate such possibility by observing the variation in the position of the (222) peak of the XRD (Fig. 7) pattern of the sintered $\mathrm{Ni}_{0.5} \mathrm{Zn}_{0.5} \mathrm{Fe}_{2} \mathrm{O}_{4}$, as this diffraction peak is very sensitive to the cations at the octahedral B-site of the spinel lattice.

The shift of the (222) peak of $\mathrm{Ni}_{0.5} \mathrm{Zn}_{0.5} \mathrm{Fe}_{2} \mathrm{O}_{4}$ by sintering at $900^{\circ} \mathrm{C}$ to lower angle in contrast to the shift of the same peak at other sintering temperatures suggests the migration of cation in fine amounts from the A to the Bsites of the spinel lattice. Similar redistribution of cations among the A and Bsites has previously been reported in $\mathrm{Ni}-\mathrm{Zn}$ ferrite, but by adopting a different synthesizing procedure [24]. Because $\mathrm{Fe}^{3+}$ has a remarkable tetrahedral site preference, the only other possibility arises because of the shift of $\mathrm{Zn}^{2+}$ from A to Bsites. A suitable cation distributionis thus proposed based on the VSM and well supported by the XRD and FTIR studies is therefore, $\left(\mathrm{Zn}_{0.35} \mathrm{Fe}_{0.65}\right)_{\mathrm{A}}\left[\mathrm{Ni}_{0.5} \mathrm{Zn}_{0.15} \mathrm{Fe}_{1.35}\right]_{\mathrm{B}}$. The detailed procedure adoptingthis cation distribution is discussed in the next section. This situation develops three possible types of exchange interactions for an $\mathrm{A}$-site $\mathrm{Fe}^{3+}$ and its twelve nearest neighboring cations situated at the $\mathrm{B}$ sites such as $\mathrm{Fe}^{3+}-\mathrm{O}^{2-}-\mathrm{Fe}^{3+}$ (strongest), $\mathrm{Fe}^{3+}-\mathrm{O}^{2-}-\mathrm{Ni}^{2+}, \mathrm{Fe}^{3+}-$ $\mathrm{O}^{2-}-\mathrm{Zn}^{2+}$ (weakest). Migration of $\mathrm{Zn}^{2+}$ in large amount would weaken the net exchange interaction between the $\mathrm{A}$ and $\mathrm{B}$ sites and might probably disrupt the antiparallel alignment between the $\mathrm{A}$ and $\mathrm{B}$ magnetic sublattices, and thus provoking magnetic frustration or a canted type spin arrangement between $\mathrm{A}$ and $\mathrm{B}$-site magnetic sublattices and dramatically decrease the magnetization as observed in the sintered powder of $\mathrm{Ni}_{0.5} \mathrm{Zn}_{0.5} \mathrm{Fe}_{2} \mathrm{O}_{4}$ at $900^{\circ} \mathrm{C}$. The feasibility for the formation of $\mathrm{NiO}$ in this case can be possibly ignored, because escaping of the $\mathrm{Ni}^{2+}$ in the form of $\mathrm{NiO}$ from the spinel lattice induces cation vacancies and for restoring the overall charge balance, and some of the $\mathrm{Fe}^{3+}$ ions reduce to $\mathrm{Fe}^{2+}$ witha high ionic radius and lower magnetic moment and preferably occupy the Bsites. Such a situation shall reduce the B-sublattice magnetic moment and hence the net magnetization. The FTIR spectroscopy (discussed later), a sensitive technique for detecting the $\mathrm{Fe}^{2+}$ species, did not show such evidence and hence the observed drop in the magnetization is cationic redistributive effect among the A and B-sites from their usual site preferences.

(c) Sintering $\mathrm{Ni}_{0.5} \mathrm{Zn}_{0.5} \mathrm{Fe}_{2} \mathrm{O}_{4}$ powders at $1,000^{\circ} \mathrm{C}$ leads to the attainment of the bulk value of magnetization (70 $\mathrm{emu} / \mathrm{gm}$ ), though the increase in the crystallite size is not much size able when compared to the crystallite size at $900^{\circ} \mathrm{C}$. This could be attributed to the effect of heating conditions in the restoration of the normal site preferences of the cations and is the principle reason for the attainment of the bulk saturation magnetization value. Heating offers thermodynamic conditions where the degree of the structure inversion in the spinel lattice becomes dependent on the ionic radius, electronic configuration of cation and their relative stabilization energies in the tetrahedral and octahedral crystalline electric fields [7], and there by overcoming the consequences of the finite size effects at the nanoscale. The observed complete magnetic saturation for the sintered powders of $\mathrm{Ni}_{0.5} \mathrm{Zn}_{0.5} \mathrm{Fe}_{2} \mathrm{O}_{4}$ at $1,000^{\circ} \mathrm{C}$ suggests the decrease in the surface layer to momentous extent and larger crystallite size in comparison with the AP ones indicates the formation of multidomain grain structure, because of the grain growth by grain boundary motion, reduction of vacancies or defects and by grain coalescence. The presence of the multidomain grains in the microstructure decreases the magneto crystalline anisotropy, promoting easier domain wall motion in response to the applied magnetic field and thereby leading to magnetic saturation when compared to the other samples. The observed least coercivity and magnetic remenence (discussed later) for the powder sintered at $1,000^{\circ} \mathrm{C}$ supported the above discussion.

The magnetic coercivity of $\mathrm{Ni}_{0.5} \mathrm{Zn}_{0.5} \mathrm{Fe}_{2} \mathrm{O}_{4}$ was observed to attain a maximum value on sintering at $800^{\circ} \mathrm{C}$ in comparison with the AP ones, whereas the coercivity decreased on further sintering. The crystallite size calculations (Table 1) indicate a single domain structure of nanograins, while its magnetization loop remained unsaturated even at a high magnetic field of $1.5 \mathrm{~T}$, representing the presence of surface layer with a typical thickness 
computed to be $\sim 1 \AA$. Thereby, the effective magnetic anisotropy is represented as $K_{e f f}=K_{v}+\frac{6}{D} K_{s}$ assuming a spherical nanoparticle where $K_{v}$ is the volume anisotropy (including shape and magneto-crystalline anisotropy); $D$ is the particle size; and $K_{s}$ is the surface anisotropy [25]. The magnetic coercivity in the single domain region (when the particle diameter is less than the critical diameter) decreases with decreasing particle size following the relation $H_{c}=g-\frac{h}{D^{2}}$ where $\mathrm{g}$ and $\mathrm{h}$ are the constants. On sintering at $800^{\circ} \mathrm{C}$, the increase in the crystallite size to $32 \mathrm{~nm}$ is well above the critical size $(22.3 \mathrm{~nm})$, indicating a multidomain structure of grains, wherein the nanocrystallite spontaneously breakup into a number of domains to reduce the large magnetostatic energy that it would have in a single domain. In the multidomain grained crystallites, the coercivity decrease with the grain size according to the relation, $H_{c}=b+\frac{c}{D}$, where $\mathrm{b}$ and $\mathrm{c}$ are the constants [17]. Hence, a decrease in the coercivity is expected by sintering at $800^{\circ} \mathrm{C}$; however, an increase in the magnetic remenence and coercivity was observed, attributing to the cation redistribution with a partial relocation of the $\mathrm{Ni}^{2+}$ ions to the octahedral sites (discussed in the next section). Such a shift would increase the magneto-crystalline anisotropy, because the tetrahedrally coordinated $\mathrm{Ni}^{2+}$ exhibit greater spin-orbit interaction compared to the octahedrally coordinated $\mathrm{Ni}^{2+}$ [26] and thereby greater magnetic anisotropy and hence high coercivity [27]. The samples heated at 900 and $1,000^{\circ} \mathrm{C}$ displayed a substantial decrease in the remenence and coercivity compared to that of the AP and sintered ones at $800^{\circ} \mathrm{C}$, and this is attributed to the increase in the grain size and improvement of the interparticle interactions between the powder particles, because of the elimination of the adsorbed organic matter on the surface of the particles, modifying the anisotropic energy barriers and also because of the cation redistribution.

\subsection{Cation Distribution Studies}

The cation distribution in spinel ferrites has been the subject of immense interest among various researchers as the imperative properties of ferrites suitable for technological applications remarkably depend on the nature of the cation and the type of the interstitial site it dwells in. The site occupancy of a cation in the spinel lattice in general depends on several factors such as cation radius, crystal field effects, polarization effects, electrostatic energies, and temperature [28]. Moreover, finite particle size effects, methods of preparation, and sintering conditions play a vital role in deciding the site occupancy, wherein an inhomogeneous distribution is observed in several ferrispinels $[3,10,24]$ with the cations occupying sites departing from their usual site preferences and thereby exhibiting several different structural, magnetic, and electrical properties at the nanoscale. Hence, in this study, examining the differences in the saturation magnetization, lattice strain, and lattice constant it is required to propose a suitable cation distribution, which could suffice the observed results. The cation distribution in spinels can be well verified in a direct, easier, and straight forward manner using the method suggested by Buerger [14] using the XRD line intensities, because the intensities of the X-ray diffracted peaks depend directly on the position of the atoms in the spinel unit cell, whereas the position of the XRD lines depends on the size of the unit cell [29]. Hence, this method is widely utilized in determining the cation distributions in several systems. According to Buerger et al., the relative integrated intensity of X-ray reflections because of the lattice plane (h k l) is according to the relation, $\mathbf{I}_{\mathbf{h k l}}=\left|\mathbf{F}_{\mathbf{h k l}}\right|^{2}$.P. $\mathbf{L}_{\mathbf{P}}$ where $\mathbf{F}_{\mathbf{h k l}}$ the structure factor, $\mathbf{P}$ is the multiplicity factor, and $\mathbf{L}_{\mathbf{P}}\left(\mathbf{L}_{\mathbf{P}}=\frac{1+\operatorname{Cos}^{2} 2 \theta}{\operatorname{Sin}^{2} \theta \cdot \cos \theta}\right.$ and $\theta$ is the angle of diffraction) is the $\operatorname{Sin}^{2} \theta \cdot \cos \theta$ Polarization factor [14]. The obtained intensities are valid strictly at $0 \mathrm{~K}$, whereas the diffraction pattern is recorded at room temperature, and hence a temperature correction might be necessary. However, the spinel ferrites, which are relatively high melting point oxides, the thermal vibration of atoms at room temperature would not significantly differ from that at $0 \mathrm{~K}$. Hence, the intensity calculations were performed neglecting the temperature factor [30, 31]. Best information regarding the distribution can be obtained on comparing experimental and calculated intensity ratios for reflections which are (i) nearly independent of the oxygen parameter, (ii) vary inversly with cation distribution, and (iii) do not differ significantly [30]. In this study, the planes (220), (422) (400), (440) are considered for cation distribution, as these planes are sensitive to distribution of cations among the tetrahedral and octahedral sites of the spinel lattice. The reflections from the planes (220) and (422) are sensitive to cations in the tetrahedral sites, whereas the reflections from the planes (400) and (440) are sensitive to cations on both the sites [29]. Therefore, the theoretical and experimental intensity ratios corresponding to $\boldsymbol{I}_{\mathbf{4 0 0}} / \boldsymbol{I}_{\mathbf{4 2 2}}$ and $\boldsymbol{I}_{\mathbf{2 2 0}} / \boldsymbol{I}_{\mathbf{4 0 0}}$ have been considered to arrive at an appropriate cation distribution. The structure factors $\left(\mathbf{F}_{\mathbf{h k l}}\right)$ was calculated using the relations available in the literature [31, 32] and are represented in the following equations.

$$
\begin{aligned}
& F_{220}=8 F_{A}+16 F_{O}(1+\cos 2 \pi 4 u) \\
& F_{311}=8 F_{A}+8 \sqrt{2} F_{B} \\
& F_{400}=8 F_{A}+8 F_{B}+32 F_{O} \cos 2 \pi 8 u
\end{aligned}
$$


Table 3. X-Ray diffraction line intensity ratio, cation distribution, A and B-site cation radius, uparameter, and theoretical lattice constant of the powder sintered $\mathrm{Ni}_{0.5} \mathrm{Zn}_{0.5} \mathrm{Fe}_{2} \mathrm{O}_{4}$.

\begin{tabular}{|c|c|c|c|c|c|c|c|c|c|}
\hline \multirow{2}{*}{ Sample } & \multicolumn{2}{|c|}{$I_{400} / I_{422}$} & \multicolumn{2}{|c|}{$I_{220} / I_{400}$} & \multirow{2}{*}{ Cation distribution } & \multirow{2}{*}{$\begin{array}{l}\mathrm{R}_{\mathrm{A}} \\
(\AA)\end{array}$} & \multirow{2}{*}{$\begin{array}{l}\mathrm{R}_{\mathrm{B}} \\
(\AA)\end{array}$} & \multirow{2}{*}{$\mathrm{u}$} & \multirow{2}{*}{$\begin{array}{l}\mathrm{a}_{\mathrm{th}} \\
(\AA)\end{array}$} \\
\hline & Obs & Cal & Obs & Cal & & & & & \\
\hline 800 & 0.89 & 0.91 & 0.875 & 0.87 & $\left(\mathrm{Zn}_{0.40} \mathrm{Ni}_{0.10} \mathrm{Fe}_{0.50}\right)_{\mathrm{A}}\left[\mathrm{Ni}_{0.40} \mathrm{Zn}_{0.1} \mathrm{Fe}_{1.50}\right]_{\mathrm{B}}$ & 0.5400 & 0.6587 & 0.3821 & 8.393 \\
\hline 900 & 0.91 & 0.92 & 0.875 & 0.88 & $\left(\mathrm{Zn}_{0.35} \mathrm{Fe}_{0.65}\right)_{\mathrm{A}}\left[\mathrm{Ni}_{0.50} \mathrm{Zn}_{0.15} \mathrm{Fe}_{1.35}\right]_{\mathrm{B}}$ & 0.5285 & 0.6634 & 0.381 & 8.387 \\
\hline 1000 & 0.89 & 0.91 & 0.872 & 0.842 & $\left(\mathrm{Zn}_{0.50} \mathrm{Fe}_{0.50}\right)_{\mathrm{A}}\left[\mathrm{Ni}_{0.50} \mathrm{Fe}_{1.50}\right]_{\mathrm{B}}$ & 0.5450 & 0.6562 & 03824 & 8.394 \\
\hline
\end{tabular}

$$
F_{440}=8 F_{A}+8 F_{B}+16 F_{O}(1+\operatorname{Cos} 2 \pi 8 u)
$$

where, $F_{A}, F_{B}$, and $F_{O}$ represent the total scattering factors of the cations at $\mathrm{A}$ and $\mathrm{B}-\mathrm{sites}$, and oxygen ions respectively, and ' $\mathrm{u}$ ' represents the oxygen positional parameter. The multiplicity factors $(\mathrm{P})$ of different planes were taken from "Principles of X-Ray Diffraction, $3^{\text {rd }}$ edition, B.D. Cullity and S.R. Stock, Prentice Hall. Inc. (2001)". An acceptable cation distribution for the $\mathrm{Ni}_{0.5} \mathrm{Zn}_{0.5} \mathrm{Fe}_{2} \mathrm{O}_{4}$ powders sintered at different temperatures which is well correlated to the saturation magnetization values were obtained by varying the proportions of the cations at $\mathrm{A}$ and B-sites and comparing the experimental and theoretical intensity ratios $\boldsymbol{I}_{\mathbf{4 0 0}} / \boldsymbol{I}_{\mathbf{4 2 2}}$ and $\boldsymbol{I}_{\mathbf{2 2 0}} / \boldsymbol{I}_{\mathbf{4 0 0}}$ and are listed in Table 3 . The A and B-site average cation radius, u-parameter, and the theoretical lattice constant were calculated based on the proposed cation distribution using the relations available in the literature [33], and the Shannon radius [34] of the cations were used in the calculations.

\subsection{IR Spectral Studies}

To verify the correctness of the proposed cation distribution using XRD and magnetization measurements, room temperature FT-IR spectral studies in the wavenumber range $300-1,000 \mathrm{~cm}^{-1}$ were performed on the sintered powders of $\mathrm{Ni}_{0.5} \mathrm{Zn}_{0.5} \mathrm{Fe}_{2} \mathrm{O}_{4}$ as shown in Fig. 8 . The spectra of all the sintered powders show the existence of two principal absorption bands, in which one peak is concentrated at the wavenumber $400 \mathrm{~cm}^{-1}$, whereas the other peak is concentrated at $\sim 600 \mathrm{~cm}^{-1}$. According to Waldron et al. [35], IR spectrum in inverse or normal spinels consists of two fundamental absorption bands in the wavenumber range $400-600 \mathrm{~cm}^{-1}$, corresponding to intrinsic vibrations of the $\mathrm{Me}-\mathrm{O}$ bond in two different environments. Thelow frequency band $\left(\gamma_{2}\right)$ concentrated at $\sim 400 \mathrm{~cm}^{-1}$ is attributed to the stretching $\mathrm{M}_{\mathrm{e}}-\mathrm{O}$ bonds at the octahedral sites, whereas the high frequency band $\left(\gamma_{1}\right)$ positioned at $\sim 600 \mathrm{~cm}^{-1}$ corresponds to the intrinsic stretching of the $\mathrm{M}_{\mathrm{e}}-\mathrm{O}$ bonds at the octahedral sites. Such an IR wavenumber absorption difference can be expected, because of the difference in the bond length $\left(\mathrm{M}_{\mathrm{e}}-\mathrm{O}\right)$ at both the sites. Smaller $\mathrm{M}_{\mathrm{e}}-\mathrm{O}$ distance in the tetrahedral

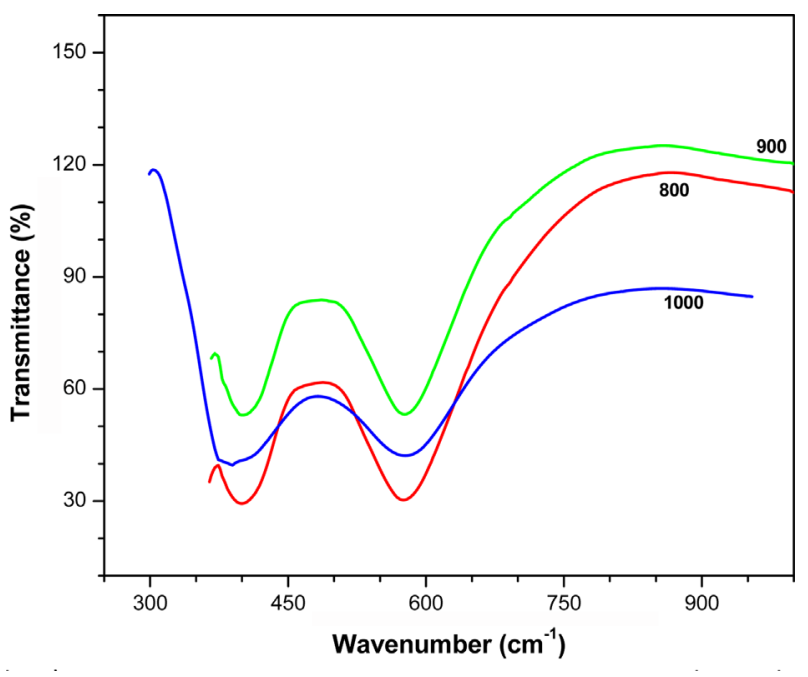

Fig. 8. (Color online) Room temperature FTIR spectra of the sintered powders of $\mathrm{Ni}_{0.5} \mathrm{Zn}_{0.5} \mathrm{Fe}_{2} \mathrm{O}_{4}$.

complex $(\sim 1.92 \AA)$ than that in the octahedral complex $(\sim 2.03 \AA)$ indicates a higher covalency between metal cations and surrounding oxygen at A-sites, and hence larger IR absorption frequency [37]. The $\mathrm{Ni}_{0.5} \mathrm{Zn}_{0.5} \mathrm{Fe}_{2} \mathrm{O}_{4}$ sample sintered at 800 and $900^{\circ} \mathrm{C}$ showed a nearly close bond lengths $\left(\mathrm{M}_{\mathrm{e}}-\mathrm{O}\right)$ at both the sites, and thereby the IR absorption peaks appeared at the same wavenumber (Table 4), whereas the $\mathrm{Ni}_{0.5} \mathrm{Zn}_{0.5} \mathrm{Fe}_{2} \mathrm{O}_{4}$ sintered at $1,000^{\circ} \mathrm{C}$ displayed a significant increase in the B-Obond length compared to the slightly in significant increase in the A-O bond length and thereby considerable increase in $\gamma_{1}$ compared to $\gamma_{2}$ (Table 4 ).

No splitting or the presence of additional shoulders in the IR absorption bands corresponding to $\gamma_{1}$ and $\gamma_{2}$ were observed for all the sintered powders, indicating a near absence of the $\mathrm{Fe}^{2+}$ ions at both the octahedral and tetrahedral sites of the spinel lattice. This is due to the fact that local deformations can occur in the $\mathrm{Fe}^{2+}$ ions because of the Jahn-Teller effect, which can lead to a noncubic component of the crystal field potential, and hence splitting of the band was not observed in this study [36]. The presence of an absorption band concentrated at $\gamma_{3}$ is attributed to the presence of the divalent metal ion in the 
Table 4. $\mathrm{M}_{\mathrm{e}}-\mathrm{O}$ distances at $\mathrm{A}$ and $\mathrm{B}$-sites, wavenumbers of absorption and force constants.

\begin{tabular}{|c|c|c|c|c|c|c|c|}
\hline \multirow{2}{*}{ Sample } & \multicolumn{2}{|c|}{$\mathrm{M}_{\mathrm{e}}-\mathrm{O}(\AA)$} & \multirow{2}{*}{$\begin{array}{c}\gamma_{1} \\
\left(\mathrm{~cm}^{-1}\right)\end{array}$} & \multirow{2}{*}{$\begin{array}{c}\gamma_{2} \\
\left(\mathrm{~cm}^{-1}\right)\end{array}$} & \multirow{2}{*}{$\begin{array}{c}\gamma_{3} \\
\left(\mathrm{~cm}^{-1}\right)\end{array}$} & \multirow{2}{*}{$\begin{array}{c}K_{t} \times 10^{5} \\
(\text { dyne } / \mathrm{cm})\end{array}$} & \multirow{2}{*}{$\begin{array}{c}K_{o} \times 10^{5} \\
(\text { dyne/cm })\end{array}$} \\
\hline & A-site & B-site & & & & & \\
\hline 800 & 1.9200 & 2.0400 & 576.72 & 399.26 & 356.83 & 1.519 & 0.963 \\
\hline 900 & 1.9044 & 2.0490 & 576.72 & 399.26 & 356.83 & 1.500 & 0.970 \\
\hline 1000 & 1.9267 & 2.3067 & 576.716 & 401.193 & 360.69 & 1.536 & 0.967 \\
\hline
\end{tabular}

octahedral complex [37]. The force constant (Table 4) usually represents the strength of the bonding and varies with the cation site radius. The higher force constant at the octahedral sites is ascribed to the fact that under favorable conditions the oxygen ions can form bonds even at larger internuclear separations. The observed variation, the u-parameter (Table 4) of $\mathrm{Ni}_{0.5} \mathrm{Zn}_{0.5} \mathrm{Fe}_{2} \mathrm{O}_{4}$ with sintering temperature, was in symmetry with the force constant values $\left(K_{o}\right.$ and $\left.K_{t}\right)$ obtained from the FT-IR spectra. An increase in the u-parameter indicates an expansion of the $\mathrm{AO}_{4}$ tetrahedra, wherein the oxygen ions are forced to move in the $<111>$ direction to accommodate the larger divalent cations in the tetrahedral sites, and the subsequent contraction of the $\mathrm{BO}_{6}$ octahedra, while a decrease indicates the opposite trend [33]. In this study, a lower u-parameter for $\mathrm{Ni}_{0.5} \mathrm{Zn}_{0.5} \mathrm{Fe}_{2} \mathrm{O}_{4}$ sintered at $900^{\circ} \mathrm{C}$ compared to those sintered at 800 and $1,000^{\circ} \mathrm{C}$ and consequent drop in the $K_{t}$ compared to $K_{o}$ was observed, supporting the proposed distribution of cations.

\section{Conclusions}

The XRD patterns of the AP and sintered powders $(800,900,1,000 \mathrm{C})$ of $\mathrm{Ni}_{0.5} \mathrm{Zn}_{0.5} \mathrm{Fe}_{2} \mathrm{O}_{4}$ synthesized by the nitrate-citrate gel auto-combustion method showed the formation of single spinel phase as confirmed from the JCPDS files. A slight decrease in the lattice constant and an increase in crystallite size were observed on sintering, and the microstrain was determined by the Hall-Williamson plot. The observed variation in the saturation magnetization of the AP and sintered samples has been ascribed to the core-shell structure morphology of the nanoparticles and the increase in the crystallite size and possible cation redistribution on sintering. The possible cation redistribution $\left(\mathrm{Ni}^{2+} / \mathrm{Zn}^{2+} / \mathrm{Fe}^{3+}\right)$ among the $\mathrm{A}$ and $\mathrm{B}$-sites of the spinel lattice creates large modification in the exchange interactions among the cations at $\mathrm{A}$ and $\mathrm{B}$-sites and might affect the antiparallel alignment of the magnetic spins of the A and B-sites, producing a large change in the magnetization as observed. The room temperature FT-IR spectra of the sintered powder $\mathrm{Ni}_{0.5} \mathrm{Zn}_{0.5} \mathrm{Fe}_{2} \mathrm{O}_{4}$ showed the existence of two characteristic absorption peaks in the wavenumber range $400-600 \mathrm{~cm}^{-1}$ and were attributed to the stretching of the $\mathrm{M}_{\mathrm{e}}-\mathrm{O}$ bonds in the tetrahedral and octahedral complexes. The variation in the force constants are well correlated to the observed variation in the uparameter, indicating the appropriateness of the cation distribution.

\section{Acknowledgements}

One of the authors (Dr. K. V. Ramesh) is thankful to University Grants Commission, India, for providing financial assistance through UGC Major research project entitled "Synthesis and study of magnetic and electrical properties of ferrites for memory and sensor applications" -F.No.42-824/2013(SR) Dt.22-03-2013.

\section{References}

[1] S. Dey, S. K. Dey, B. Ghosh, P. Dasgupta, A. Poddar, V. R. Reddy, and S. Kumar, J. Appl. Phys. 114, 093901 (2013).

[2] A. Yang, C. N. Chinnasamy, J. M. Greneche, Y. Chen, S. D. Yoon, Z. Chen, K. Hsu, Z. Cai, K. Ziemer, C. Vittoria, and V. G. Harris, Nanotechnology 20, 185704 (2009).

[3] V. Šepelák, A. Feldhoff, P. Heitjians, F. Krumeich, D. Menzel, F. J. Litterst, I. Bergmann, and K. D. Becker, Chem. Mater. 18, 3057 (2006).

[4] J. Jacob and M. A. Khadar, J. Appl. Phys. 107, 114310 (2010).

[5] C. Upadhyay, H. C. Verma, V. Sathe, and A. V. Pimplae, J. Magn. Magn. Mater. 312, 271 (2007).

[6] M. S. R. Prasad, B. B. V. S. V. Prasad, B. Rajesh, K. H. Rao, and K. V. Ramesh, J. Magn. Magn. Mater. 323, 2115 (2011).

[7] Z. Beji, L. S. Smiri, N. Yaacoub, J. M. Grenèche, N. Menguy, S. Ammar, and F. Fiévet, Chem. Mater. 22, 1350 (2010).

[8] S. Gubbala, H. Nathani, K. Koizol, and R. D. K. Misra, Physica B 348, 317 (2004).

[9] S. Thakur, S. C. Katyal, A. Gupta, V. R. Reddy, S. K. Sharma, M. Knobel, and M. Singh, J. Phys. Chem. C. 113, 20785 (2009).

[10] C. Upadhyay, H. C. Verma, and S. Anand, J. Appl. Phys. 95, 5746 (2004).

[11] B. T. Naughton, P. Majewski, and D. R. Clarke, J. Am. Ceram. Soc. 90, 3547 (2007). 
[12] M. S. R. Prasad, B. R. Babu, K. V. Ramesh, and K. Trinath, J. Supercond. Nov. Magn. 27, 2735 (2014).

[13] JCPDS Card No. 08-0234

[14] Principles of X-Ray Diffraction, B. D. Cullity, S. R. Stock, Prentice Hall Inc. (2001).

[15] A. S. Albuquerque, J. D. Ardisson, W. A. A. Macedo, and M. C. M. Alves, J. Appl. Phys. 87, 4352 (2000).

[16] X-Ray Diffraction - A Practical Approach, C. Suryanarayana and M. Grant Norton, Plenum Press (1998).

[17] M. George, A. M. John, S. S. Nair, P. A. Joy, and M. R. Anantharaman, J. Magn. Magn. Mater. 302, 190 (2006).

[18] C. Liu and Z. J. Zhang, Chem. Mater. 13, 2092 (2001).

[19] R. H. Kodama, A. E. Berkowitz, E. J. McNiff, Jr., and S. Foner, Phys. Rev. Lett. 77, 394 (1996).

[20] M. Muroi, R. Street, P. G. McCormick, and J. Amighian, Phys. Revi. B 63, 184414 (2001).

[21] R. Swaminathan, J. Woods, S. Calvin, J. Huth, and M. E. McHenry, Adv. Sci. Tech. 45, 2337 (2006).

[22] R. Swaminathan, M. E. McHenry, S. Calvin, M. Sorescu, and L. Diamandescu: Proc. ICF-9, Amer. Ceram. Soc. 847 (2005).

[23] G. A. Petitt and D. W. Forester, Phys. Rev. B 4, 3912 (1971).

[24] K. B. Modi, T. K. Pathak, N. H. Vasoya, V. K. Lakhani, G. J. Baldha, and P. K. Jha, Ind. J. Phys. 85, 411 (2011).

[25] S. Bedanta and W. Kleeman, J. Phys. D: Appl. Phys. 42, 13001 (2009).
[26] M. Dessai, S. Prasad, N. Venkataramani, I. Samajdar, A. Nigam, K. Keller, N. Krishnan, R. B. Saitovitch, E. M. Pujada, and B. R. A. Rossi, J. Appl. Phys. 91, 7592 (2002).

[27] Introduction to magnetic materials, B. D. Cullity, and C. D. Graham, Wiley-IEEE Press (2008).

[28] K. E. Sickafus and J. M. Wills, J. Am. Ceram. Soc. 82, 3279 (1999).

[29] V. K. Lakhani and K. B. Modi, J. Phys. D: Appl. Phys. 44, 245403 (2011).

[30] R. H. Kadam, A. P. Birajdar, S. T. Alone, and S. E. Shirsath, J. Magn. Magn. Mater. 327, 167 (2013).

[31] S. M. Patange, S. E. Shirsath, S. S. Jadhav, and K. M. Jadhav, Phys. Status Solidi A 209, 347 (2012).

[32] M. Inagaki and S. Naka, J. Inorg. Nuc. Chem. 35, 3009 (1973).

[33] Magnetic Ceramics by Raul Valenzula, Cambridge University Press (1994).

[34] H. St.C. O’Neill, and A. Navrotsky, American Minerologist 68, 181 (1983).

[35] R. D. Waldron, Phys. Rev. 99, 1727 (1955).

[36] M. C. Chhantbar, U. N. Trivedi, P. V. Tanna, H. J. Shah, R. P. Vara, H. H. Joshi, and K. B. Modi, Indian J. Phys. 78, 321 (2004).

[37] S. S. Bhatu, V. K. Lakhani, A. R. Tanna, N. H. Vasoya, J. U. Buch, P. U. Sharma, U. N. Trivedi, H. H. Joshi, and K. B. Modi, Ind. J. Pure Appl. Phys. 45, 596 (2007). 